\title{
Prospect on the Inheritance History and Development Trend of Fish Drum Dance, a Folk Dance in Hong-ze Lake, Jiangsu
}

\author{
Can Zhang \\ Huaiyin Normal University, Huaian Jiangsu, 223000, China
}

Keywords: Jiangsu, Folk dance, Hong-ze fish drum dance, Inheritance history, Development trend.

\begin{abstract}
This article starts from the inheritance of Jiangsu folk dance with Hong-ze fish drum dance as the example, makes appropriate exploration on inheritance dilemma in current society, and points out the future development trend of Jiangsu folk dance, with the prospect to enrich studies of Jiangsu folk dance and to form more profound understanding of Jiangsu folk-traditional culture.
\end{abstract}

\section{Introduction}

Hong-ze fish drum dance is a folk dance of Han nationality in Jiangsu province, an ancient sacrificial dance in early Hong-ze Lake area performed by the wizard to burn incense and papers for fishermen's redeeming wishes or for altar pray. Initially originated in Bancheng area of Sihong County (current Bancheng Town) Jiangsu province, Hong-ze fish drum dance has formed and developed gradually with fishermen's production and life in Hong-ze Lake area. Bancheng County is located in the west cost of Hong-ze Lake, the capital of the State of Xu in Spring and Autumn period, as well as the birthplace of family name and culture of "Xu" in China. There are Xucheng field, Sword hanging stand, Grey Swan grave and other ancient relics of Xu culture. Special geographical environment and profound cultural background has made fishermen's traditional sacrificial activities prevailing. Local people invite God and expel the evil spirit in the way of offering sacrifices to gods for blessings of fishermen's safeness when fishing on the lake and their celebration of returning with harvest.

\section{Historical inheritance of Jiangsu folk dance}

Jiangsu province is located in Chinese eastern coastland with excellent cultural traditions. Gradually influenced by the Wu culture since from the Spring and Autumn period, a kind of cultural system which can influence and restrict mutually with Yue and Chu culture has produced active impact on in-depth study on Jiangsu folk dance. Jiangsu folk dance has long history. In long-term historic evolution and inheritance process, constant integration and evolution of various types of dance have provided relevant developmental chance for Jiangsu folk dance ${ }^{[1]}$. Generally speaking, folk dance in Jiangsu province, influenced by its own comprehensive properties, can be specifically divided into several types: self-entertainment, religiousness, skill, and simulation of animal forms. Analyzing the self-entertainment, it can be found that, dance with self-entertainment can often combine performance demands to make free adjustment with strong randomness. For example, well-known flower-drum, flower lamp and flower basket have won grass-root people's favor. But religious dance appeared at the earliest in ancient times mainly for sacrificing land, praying for harvest and thanking gods. After inheritance from generations to generations, it has even penetrated into relevant Buddhist culture and Taoist culture in Chinese history, helping Jiangsu folk dance win more chances for Jiangsu folk dance to develop. In the dance performance skills, Jiangsu folk dance can be specifically divided into two types: skill and simulation. Simulation of animals are mainly achieved through organic simulation of daily life conditions and movements of relevant objects to show up the 
characteristic of an original ecology dance which usually depends on props during the performance process following ancient traditional dance of "dance image" as the embodiment of ancient dance performance in totem awareness. This kind of dance is usually hidden within specific animal-form props, performed through zoosemy. For example, the Lion dance and Dragon dance popular in South and northern Suzhou of Jiangsu area are both typical representation of simulation-based dances. Skill-based dance has developed relatively mature with systematic dance routine and manifestation pattern formed, showing certain entertainment function. It has gradually absorbed relevant elements of martial arts and acrobatic performance during its development process with the routine of mechanical action as the performance foundation. Some dance performers select to use weapons to dance. For example, broad-sward dance widespread in Wuxi, knives and forks dance, fisher-boat sword pulp inherited and broadcasted in Zhenjiang Dantu area, and Tiaomafu popular in Nantong area, are representative of the establishment of skill-based folk dance in Jiangsu area. The inheritance status of Jiangsu folk dance is influenced by foreign dancing culture elements. Dance in different areas is also influenced by local national culture and manners and customs. Martial art type dace has been widely exchanged in different areas, which has laid solid foundation for extensive inheritance of weapon dance in modern society.

Hong-ze Lake fish drum originated and developed in Hong-ze Lake area mainly distributed some villages and towns around the lake such as Bancheng Town of Sihong County, and Laozishan Town of Hongze County. Early inheritance system of fish drum was familial, i.e. fathers passed down to sons, and the senior handed over to the juniors orally from generations to generations. But in the late Qing Dynasty and the Republic of China, with the flourishment of fish drum in the lake area, the inheritance broke through family system with the phenomenon of taking external apprentices emerging. At that time, about 1000 fish drum troupes were active in the lake area with up to thousand people participated. After liberation, fish drum dance has been excavated mainly by professional culture workers and organizing personnel. It has absorbed techniques of folk dance on the basis of maintaining characteristics. Especially after the reform and opening-up, organization, performance and innovation in each year have helped the inheritance of ancient artistic performing pattern in the lake area continues to this day.

\section{Inheritance dilemma of Jiangsu folk dance in current stage}

\section{Changes of social environment have influenced the inheritance of Jiangsu folk dance}

With the construction and development of social economy, agricultural productivity has been liberated gradually. It has promoted the life style of mass peasants change particularly. Some rural young labor forces enter cities for working, and even some young people who choose to stay in the countryside do not choose to take up agricultural activities. Relevant survey researches show that, most population in rural areas are immigrating into cities gradually working for others or doing business with a small capital around cities ${ }^{[2]}$. There exists the same phenomenon as well in the area where Jiangsu folk dance has been mainly broadcasted. Changes of social environment have forced some folk artisans in Jiangsu province to give up the inheritance of folk dance culture. They turn from folk dance practitioners into folk dance lovers and perform only in spare time as hobbies. Especially influenced by new life concepts, the inheritance of folk dance is being neglected. This has severely impacted the inheritance and broadcasting of Jiangsu folk dance, and the survival and development of folk dance have been greatly limited.

\section{There appeared fault phenomena among orally inherited folk dance culture}

Folk dance culture in Jiangsu area are mainly inherited in the way of artisan's orally teaching. The special inheritance method has been influenced by social environment and other relevant factors in current materialistic society. This has caused serious fault phenomena among dance inheritance artisans. Influenced by the bad effect of marketing economy, broadcasting mode of free inheritance in 
the past has no longer existed. Loose master and apprentice teaching is exiting from the historic stage gradually. Order education is gradually developing into the major way of Jiangsu folk dance inheritance, cultivating a large amount of successors of dance art to a large extent. But as a whole, there exist relatively few organizations working on folk dance inheritance and training in Jiangsu area so that the effect of inheritance of multiple folk dance in Jiangsu is not ideal. This kind of inheritance mode can still not promote folk dance to be widely popularized in a short time, which has limited the effective implementation of folk dance inheritance work.

\section{The accelerating process of urbanization makes the social public gradually forget local accent and provincialism}

The development of urbanization has to a certain degree promoted the reform of basic economic structure in China, and made people in Jiangsu area start enjoying the achievement of urbanization construction in modern society with people's life concept, life style and the cultural quality education in Jiangsu province changed ${ }^{[3]}$. Under this social background, folk dance rooted in Jiangsu agricultural society is full of local flavor which is the exact reason of its widespread popularization among mass peasants, even prevailing in Hubei and Hunan areas. But meanwhile, we should profoundly realize that, Jiangsu folk dance system is complicated so that its inheritance and broadcasting will be inevitably restricted by many factors with certain social and historical limitations. For example, royalism and ideas of publicizing integrity and righteousness, and even the broadcasting of local feudalistic superstitions are gradually losing their due dissemination significance in current urbanization process. Under the circumstance that social public are gradually forgetting local accent and provincialism, the inheritance and broadcasting of folk dance are greatly limited.

\section{Prospects on the development trend of Jiangsu folk dance}

\section{Development trend of all-people participation in protecting traditions}

Throughout history, the broadcasting and inheritance of Chinese folk dance have been closely related with politics. The attitude of government divisions is greatly influencing the protection and inheritance of folk dance. Investigations and researches show that currently troupes in Jiangsu area have cultivated some dancers for commercial performance to further improve economic benefits for the use of troupe development. But the economic benefits they have obtained are very few. Government divisions must take measures to increase fund investment and policy support to guarantee the inheritance and broadcasting of Jiangsu folk dance. It can promote the social public to form profound understanding of the inheritance of folk dance on the basis of providing good conditions for the inheritance and broadcasting of folk dance so as to actively get engaged into the work of protecting traditional folk dance culture art under the call of the country, to promote better inheritance of folk dance art in Jiangsu province.

\section{Natives and derivatives present synergetic development trend}

Countryside is the birthplace of Jiangsu folk dance. Appropriately carrying out folk dance activities, integral repair and protection of the survival environment of folk dance culture on the basis of China' focusing more on intangible cultural heritage protection is one of the central work of tangible cultural heritage. Based on this, as folk artisans are living carriers of the inheritance of Jiangsu folk dance, the chief work of protecting and inhering folk dance is to protect the inheritors of folk dance. Meanwhile, as Jiangsu folk dance is originated from local special historic and cultural environment, it requires to focus on protecting traditional culture in various areas in Jiangsu so as to guarantee the extensive inheritance of folk dance, so as to create good native development space for the inheritance of folk dance $^{[4]}$. Besides, during the broadcasting and inheritance of Jiangsu dance, it should be known that things' development will inevitably change due to the influence from external environment. So folk 
dance has certain original and native forms and also specific derivative forms. So when inheriting originally native dance, people should focus on combing the derivation mentality to develop and innovate native dance to strengthen the vitality of Jiangsu folk dance which is an intangible cultural heritage. That is to say, during the future inheritance of Jiangsu folk dance, natives and derivatives present synergetic development trend, which will promote better effect of the inheritance of Jiangsu folk dance.

\section{Development trend of consciously toward cities}

Jiangsu folk dance culture as Chinese intangible cultural heritage survives mainly in a living form. The living cultural heritage has developed from initially individual inheritance into extensive broadcasting in peak time, and then facing some development difficulties in nowadays society. It is always a cultural conscious activity with certain consciousness and purposiveness. Therefore, during broadcasting and inheriting Jiangsu folk dance, cultural consciousness plays an extremely important role. Only understanding the importance of cultural consciousness can cultural inheritance work be with certain spiritual substance with cultural inheritance methods be well transformed ${ }^{[5]}$. For folk dance in Jiangsu areas, under the mentality of cultural consciousness, folk dance can acquire good development from broadcasting in rural areas to urban areas. Therefore, consciously going into the urban as one of the future development trends of Jiangsu folk dance is making important influence on the inheritance of Jiangsu folk dance.

Hong-ze Lake fish drum dance has a history of over 800 years mainly through the constant inheritance by folk artisans with the method of family inheritance from the senior orally instructing to the junior. Inheritors have constantly evolved during the practice of production and life, and absorbed musical and folk art types such as fisherman's songs, elbow drum, talking and singing in later performance of fish drum dance, so that the performance of fish drum dance has developed maturely and evolved into the form of stage and squire performance. It has shown that fish drum dance, the folk art form with Hong-ze Lake characteristic, is full of strong vitality. "Fishermen are troubled with money cannot work so they arrange boats or burn papers." And fish drum performance takes up the dominance in the ceremony of burning incents and papers. It can be seen that fish drum dance has been deeply entrenched into the fishermen's mind who live in Hong-ze Lake area.

\section{Conclusion}

In current society, influenced by multiple social environment factors and historic cultural factors, Chinese large amount of folk dance have gradually been faced up to inheritance difficulties and even extinction. Therefore, under this background, development dilemma in current folk dance broadcasting and inheritance work should be clarified if Jiangsu folk dance can obtain better development. Then actively carry out inheritance and protection work with the support of government divisions to provide good conditions for the inheritance of Jiangsu folk dance and to promote more development achievements in new era. Old folk artisan of fish drum in lake area are few in number at old age. In addition, young people are not willing to sing fish drum. So fish drum dance is faced up with the situation of inheritance extinction. Furthermore, fishermen do not live in a fixed area so that it is hard for concentrated rehearsal. This is bad for the long-term inheritance of fish drum dance art. So far, Hong-ze Lake fish drum dance has been listed as municipal intangible cultural heritage reserve program. This ancient artist performance form has been favored by people in the lake area. Its continuous inheritance and development has profound significance for further studying Hong-ze Lake folk culture and folk-custom, and enriching the cultural life in lake area.

\section{Acknowledgments}

This article is Jiangsu Provincial National Social Science Foundation Youth Project. Jiangsu folk dance inheritor's oral history study. No. 13YSC018. 


\section{References}

[1] Xu Feng. Protection and promotion of Huachuan, the folk dance in coastal area of Jiangsu. Literature and art for the populace, 2016(8):65.

[2] Yang Xiumin. Reflection on folk dance style teaching. Music Space, 2014(15):182-182.

[3] Li Peishan. Brief discussion on rules and development trend of folk dances of Chinese ethnic groups. Northern Music, 2015(3):191-191.

[4] Liang Yue. Folk dance, speaking of folk, --brief discussion on the relation between folk dance and folk life. The Science Education Article Collects, 2015(30):165-166.

[5] Guan Jian. Discussion on the feasibility of introducing Jiangsu traditional folk dance into art college classroom. New Course (Education academy), 2013(3):62-63. 